\title{
Os critérios de avaliação da pós-graduação em psiquiatria pela Capes
}

Com a modificação dos critérios para a avaliação da pósgraduação em psiquiatria, há quatro anos, ocorreram mudanças profundas na maneira como os cursos são credenciados. Um grande debate foi gerado sobre se os critérios da Capes poderiam, ou mesmo se deveriam, ser aplicados à psiquiatria. Hoje, essa discussão não cabe mais e a grande questão é como vamos nos adaptar a esses critérios. Como tive o privilégio de participar, representando a psiquiatria, de uma reunião da Capes em agosto de 2000, na qual foi feita uma avaliação de todos os cursos de pós-graduação no Brasil, achei que valeria a pena discutir esses critérios.

Em primeiro lugar, é importante saber que a Capes vem buscando critérios objetivos de excelência na avaliação de todos os cursos de pós-graduação no Brasil. A psiquiatria está dentro de um grupo chamado de Medicina II, junto com neurologia, nutrição, pediatria, radiologia, hematologia e reumatologia, moléstias infecciosas e imunologia. Esse grupo busca criar critérios comuns de avaliação.

As áreas que são consideradas para avaliação são:

1. Proposta do programa: aqui avalia-se a coerência e a consistência da proposta, os objetivos e a inserção regional, além da infra-estrutura, como biblioteca e financiamento. Os critérios aqui são qualitativos e o avaliador faz um julgamento crítico da proposta.

2. Corpo docente: aqui busca-se avaliar a qualidade dos docentes. Para o programa receber "muito bom", na composição dos docentes deve existir 100\% de doutores e a maioria com mais de cinco anos de titulação. Além disso, pelo menos $80 \%$ dos docentes devem ser NRD6 (isto é, contratados por mais de 40 horas). Menos de $20 \%$ dos docentes podem ser de outras instituições.

3. Atividade de pesquisa: a adequação e a abrangência dos projetos passa por uma avaliação qualitativa, assim como o vínculo entre as linhas de pesquisa e os projetos. É verificada a adequação da quantidade de linhas e de projetos em relação à dimensão e à qualificação dos NRD6. A avaliação da participação dos discentes nos projetos de pesquisa é feita quantitativamente e o conceito "muito bom" é dado quando mais de $90 \%$ dos alunos de mestrado e doutorado estão inseridos em projetos de pesquisa. Bolsistas de iniciação científica fazem parte da avaliação e deve-se buscar um bolsista para pelo menos dois docentes NDR6.

4. Atividade de formação: faz-se uma avaliação qualitativa da estrutura curricular em relação à proposta do programa e de suas áreas de concentração. Deve-se buscar que mais de $80 \%$ dos docentes em NRD6 estejam orientando alunos. As avaliação das atividades letivas e de orientação nos cursos de graduação é feita de uma forma qualitativa.
5. Corpo discente: um sinal de alerta na relação entre o corpo discente e a dimensão dos NRD6 é quando existe mais de cinco alunos por professor. O número de titulados deve ser maior do que $20 \%$ do corpo de alunos por ano e as desistências ou abandonos não podem passar de 5-10\%.

6. Teses e dissertações: existe uma avaliação qualitativa para o vínculo entre as teses e os projetos de pesquisa. O tempo médio de titulação para mestrado deve ser menor do que 30 meses e o de doutorado menor do que 48 meses. Deve-se buscar que exista pelo menos um titulado por ano para cada dois docentes NRD6, para se obter o "muito bom". As bancas examinadoras também são avaliadas usando critérios qualitativos, devendo-se sempre ter avaliadores externos.

7. Produção intelectual: essa foi a área que mereceu maior discussão. Buscou-se criar critérios para avaliar o impacto das publicações usando o Journal of Citation Report. Para isso, criou-se o índice abaixo, que é específico para o Medicina II.

Internacional A: artigos com índice de impacto maior do que 1. Cada artigo com essas características recebia a equivalência de 100 pontos;

Internacional $B$ : artigos com índice de impacto entre $0,4 \mathrm{e}$ 0,99 . Cada artigo com essas características recebia a equivalência de 50 pontos;

Internacional $C$ : artigos com índice de impacto entre $0,1 \mathrm{e}$ 0,39 . Cada artigo com essas características recebia a equivalência de 10 pontos.

Para os artigos nacionais buscou-se classificar as revistas de acordo com a indexação da Lilacs. Para isso, criou-se o seguinte critério:

Nacional A: Lilacs + referência da área. Optou-se pela Revista Brasileira de Psiquiatria como a revista de referência na área, pois ela sofreu modificações substanciais nos últimos anos. Cada artigo nessa revista recebia a equivalência de 10 pontos.

Nacional B: Lilacs + não referência. As revistas indexadas pelo Lilacs em psiquiatria são: Arquivos de Neuropsiquiatria, Jornal Brasileiro de Psiquiatria, Psiquiatria Biológica, Revista de Psiquiatria do Rio Grande do Sul, Revista Brasileira de Psicanálise, Informação Psiquiátrica, Revista de Psiquiatria Clínica e Revista de Psicanálise. Cada artigo nessas revistas recebia 2 pontos.

Nacional C: outras publicações não indexadas e que recebiam 1 ponto.

De posse de todas essas classificações dos artigos publicados por cada programa somou-se os pontos e dividiu-se pelo número de docentes NRD4 ou superior. O programa deveria buscar pelo menos um artigo internacional com fa- 
tor de impacto maior do que 1 (ou pontuação equivalente, ou seja, 100 pontos) para cada docente, para receber o conceito "muito bom". Além do número de artigos, faz-se uma avaliação qualitativa da distribuição da autoria entre os docentes, para que não haja excessiva concentração em relação a poucos docentes. O ideal é que todos ou pelo menos a maioria dos docentes tenham regularidade de publicação. A produção intelectual é a parte mais importante da avaliação e representa $30 \%$ do peso do processo.
A grande vantagem do processo que ocorre no momento na Capes é a transparência do procedimento de avaliação e a relativa objetividade dos critérios usados. Nós da psiquiatria podemos argumentar contra ou a favor desse ou daquele critério, mas não vamos conseguir ficar de fora. Todos os detalhes dessa avaliação já estão disponíveis no site da Capes (www.capes.gov.br).

Ronaldo Laranjeira Departamento de Psiquiatria da Unifesp/EPM 